\title{
Preface by the Guest Editors
}

A professor who fulfills his or her aim to transmit knowledge is a happy professor. Prof. dr. Gerard Boter is such a happy professor, regardless of the size of his audience. Whether it is the hall of the sumptuous renaissance Teatro Olimpico at Vicenza, where he once, dressed as Epictetus, delivered a lecture to hundreds of people, or a brick-walled classroom at the fourteenth floor of the Vrije Universiteit, where he sat down with a single student for a tutorial in classical philology, his motto as a teacher is 'sat mihi unus'. The present special issue of Mnemosyne is an homage to Prof. dr. Gerard Boter, to whom emeritus status was accorded in September 2019 as a professor in Ancient Greek language and literature at the Faculty of Humanities of the Vrije Universiteit, Amsterdam. As guest-editors of Mnemosyne, we collected essays by colleagues of Gerard Boter from various countries, written especially for the occasion and addressing different aspects of the relationship between the Greek and Roman cultures inor, in some cases, up to - the Imperial period.

Let us first briefly dwell upon Gerard Boter's career as university professor and secondary school teacher. We will begin our palmares (to adopt the vocabulary of bicycle racing - a favorite pastime of Gerard) in the 1970s. After graduating at the Eerste Christelijk Lyceum in Haarlem, Gerard studied Classics at the Vrije Universiteit from 1972 to 1980 , with the intention to become a secondary school teacher of Greek and Latin. Fearing to remain unemployed as a teacher, he devised a plan B. Together with his classmate at the Vrije Universiteit Ineke Sluiter, he decided to obtain a driving license for large transport vehicles such as buses and trucks. While they greatly enjoyed the lessons, in the end they did not have to resort to plan B-both would eventually become full professors of Greek at Dutch Universities.

While working as a school teacher of Latin and Greek, Gerard obtained a scholarship from ZWO (Dutch Research Council) to prepare a PhD thesis on the textual transmission of Plato's Republic. Dick Schenkeveld and Siem Slings acted as his doctoral advisors. His doctoral thesis, completed in 1986, has been fundamental for Siem Slings's OCT-edition of the Republic, which was published in 2003, shortly before Slings's untimely death. After his PhD, Gerard continued to work as a teacher, first at the Gymnasium Sorghvliet in The Hague, then at the Vossius Gymnasium in Amsterdam. Meanwhile, he worked on a new edition of Epictetus' Encheiridion and three Christian adaptations 
(published in 1999 by Brill and in 2007, without the Christian additions, by Teubner).

In 2001, Gerard Boter was appointed as a lecturer at the Vrije Universiteit in Amsterdam, and in 2004 as a full professor of Ancient Greek language and literature. Yet, even as a full professor he continued to teach one class at the Vossius Gymnasium - which shows his strong commitment to secondary education. Between 2008 and 2018 he acted as chairman of the Classics committee of the national College for Tests and Exams (CvTE), responsible for the development of the yearly national school exams. Together with Rob Brouwer, he also published a Dutch translation of Epictetus' Collected Works (Amsterdam 2011, at Athenaeum-Polak \& Van Gennep).

Gerard is known by his students and colleagues for his infectious humor and his indestructible good mood, incessantly brimming with hilarious anecdotes, but also strongly involved in the ups and downs of their personal life. Two other conspicuous characteristics of Gerard should not pass unmentioned. The first can be best defined, in the style of Theophrastus' Characters, as 'Boter the Better'. Adding a 31th character to Theophrastus' list, we might characterize 'Boter the Better' along the following lines: 'The Better has a slim build and is keen on riding a racing bicycle. Yet his passion is ignited whenever an intellectual showdown takes place. Betting is his great joy in life-provided he wins.' Indeed, in his capacity as 'Boter the Better' Gerard has won umpteen installments (we all lost count) of the yearly national classical pubquiz (the 'Ken-Uw-Klassieken Pubquiz') in a row.

The second characteristic feature of Gerard to be mentioned is intimately connected to the term 'Boterette', better known as 'Gerardje' or 'Botertje' among his Dutch colleagues. A 'Boterette' is a tiny typographical error in a proof, which has been missed by everyone else, but is unfailingly noticed by Gerard Boter. The term eventually gave rise to an oft-heard stock phrase in our department: 'I enjoyed reading your paper very much, but I still spotted some Boterettes'. It goes without saying that both characteristic features are part and parcel of Gerard's eminent qualities as a Classical philologist.

As we write, Gerard is finishing his new Teubner-edition of Philostratus' Life of Apollonius of Tyana. After this project, it is his intention to prepare a new edition of Plato's Timaeus. To put it in the language of textual editing: this special issue is certainly not meant as a full stop, but merely as a comma in Gerard's scholarly life.

The present issue in honour of Gerard Boter covers themes related to his philological interest in literature from the Graeco-Roman period, weaving a geographical, as well as a thematical web: geographically from the West to the East - from Rome to Smyrna, Bithynia, and Syria—and from the East to 
the West-migrants traveling through the Mediterranean; thematically from Samosata-now submerged by the Atatürk Dam like Plato's Atlantis-to Plato's Myth of Er and the colours of the planets up to the time of Proclus. In the meantime, we encounter highly diverse personalities such as grammarians, philosophers and emperors, and we learn about their education, reputation and remuneration.

\section{Rutger Allan and Emilie van Opstall}

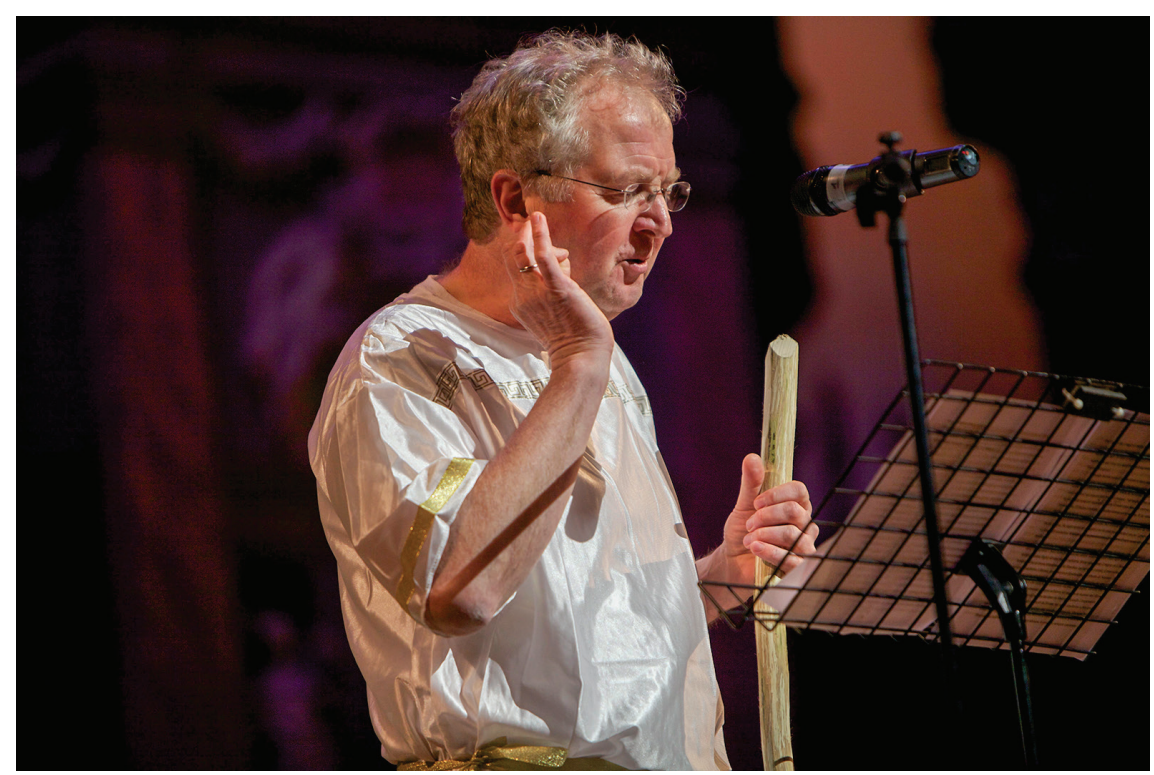

Gerard Boter dressed as Epictetus at the Teatro Olimpico in Vicenza, 2013 PHOTO CLASSICI CONTRO/TEATRO OLIMPICO VICENZA, ITALY 